\title{
Analysis of economic convergence of Islamic justice in selected Islamic countries
}

\author{
Mohammad Reza Alizadeh Emamzadeh*
}

\author{
${ }^{*}$ Correspondence: \\ mohamadrezaalizadeemamzade \\ @yahoo.com \\ Department of Islamic Education, \\ Mahabad Branch, Islamic Azad \\ University, Mahabad, Iran
}

\begin{abstract}
Justice is the most important principle in Islam and measures the extent to which decisions in Islamic countries comply with Islamic doctrine. Economic justice is a subdomain of justice and is further subdivided to distributive justice. Distributive justice implies that improvement in economic well-being of an individual occurs to the detriment of another's. The present study investigates economic convergence of Islamic justice in selected Islamic countries (Albania, Bangladesh, Azerbaijan, Egypt, Guinea, Iran, Iraq, Jordan, Kazakhstan, Kosovo, Kyrgyzstan, Malaysia, Maldives, Niger, Pakistan, Senegal, Tajikistan, Turkey, Yemen And Tunisia) during 1995-2015 using beta-type convergence and generalized method of moment. It is argued that growth rate of income distribution in communities that suffer from bad income distribution system will move in the long run towards fair distribution. Results of absolute beta convergence indicate convergence of Gini coefficient at rate of 0.31 . The Gini coefficient is significant at $1 \%$. Moreover, results of conditional beta convergence reveal convergence of Gini coefficient. Inflation rate and GDP positively affect this convergence.
\end{abstract}

Keywords: Islamic justice, Economic convergence, Islamic countries, Beta-type convergence, Generalized method of moment

JEL Classification: O11, C22, D33

\section{Introduction}

Following WWII, underdeveloped countries tried to achieve high economic growth rates to be more prosperous. According to Solow-Swan, economic growth rate is higher in poor countries than rich ones, implying that it will be more convergent in the long run. This was the initial idea of convergence which was later extended to other domains including price and income distribution.

Justice is defined in Islamic thought as administration and protection of rights against wrongs and oppression and is the golden mean between the extremes of excess and deficiency (Sajjadi 1983, p. 274-275). It is also defined as equality, fairness and impartiality, on the one hand, and balance, moderation, proportionality, and compliance with order, on the other. Justice is a religious and rational conception that provides the basis for evaluation of religions and is a virtue to be realized in an ideal state. Thus, it lies at the heart of religious doctrine by which communal acts are measured to comply with Islamic thought. Economic justice is a major sub-domain of justice that covers social justice as it

(c) The Author(s) 2020. This article is licensed under a Creative Commons Attribution 4.0 International License, which permits use, sharing, adaptation, distribution and reproduction in any medium or format, as long as you give appropriate credit to the original author(s) and the source, provide a link to the Creative Commons licence, and indicate if changes were made. The images or other third party material in this article are included in the article's Creative Commons licence, unless indicated otherwise in a credit line to the material. If material is not included in the article's Creative Commons licence and your intended use is not permitted by statutory regulation or exceeds the permitted use, you will need to obtain permission directly from the copyright holder. To view a copy of this licence, visit http://creativeco mmons.org/licenses/by/4.0/. 
explains interests, desires, state of existence and competition between individuals within a given society. Distributive justice is an important index of economic justice. It denotes a situation in which too much possession of something by someone leads to deprivation of another of the same thing. Distributive justice is best applied in allocating rare products, services, resources and goods that directly or indirectly cause conflicting demands. Therefore, it calls for fair distribution of material goods among all social members (Eivazlou 2010, p. 7-12).

Establishing Islamic economic justice has always been the prime objective of Islamic governing system. A principal aspect of Islamic justice in economics is distribution of income, which means fair allocation of income to families within a society or between countries. Local distribution of income to realize justice and promote effectiveness is also important.

Islamic countries host a major part of world population. An analysis of income distribution and its related transformations in these communities contributes to determining its status and promoting distributive justice. It is imperative to identify communities with unfair distribution in order to establish policies to achieve a more balanced distribution. In addition to having a fair income distribution system, it is expected that Islamic countries adopt a more long-term convergent approach towards distribution. In other words, communities that score low at growth rate of income distribution index should try in the long run to achieve mean growth rate. Gini coefficient is used for analyzing income distribution. Albu (2012) studied convergence of Gini coefficient in EU countries during 2000-2011 and found an accentuated convergence inside the EU-10 group, but a significant divergence inside EU-15. Similarly, Chambers and Dhongde (2016) studied convergence of Gini coefficient in some countries and reported positive results. Thus, considering the gap in the literature and lack of studies on Islamic countries, the present study examines convergence of income distribution as an index of economic justice in selected Islamic countries (Albania, Bangladesh, Azerbaijan, Egypt, Guinea, Iran, Iraq, Jordan, Kazakhstan, Kosovo, Kyrgyzstan, Malaysia, Maldives, Niger, Pakistan, Senegal, Tajikistan, Turkey, Yemen and Tunisia) during 1995-2015 using beta-type convergence and generalized method of moment.

The rest of the paper is structured as follows. Section 2 provides the review of the literature. Section 3 deals with research methodology. Section 4 is the analysis of results. Finally, concluding remarks and suggestions are given in Sect. 5.

\section{Review of literature}

In this section, theoretical basis and empirical studies are provided in brief.

Ramsey (1928) founded the basic growth pattern and later Solow (1956) and Swan (1956) developed it. Exogenous Growth Model, known as neoclassic growth model, was the basic growth model. In neoclassic model with decreasing efficiency, as in SolowSwan model, rate of growth per capita income of a country is conversely related to initial level of per capita income. Therefore, in the absence of external shocks, level of per capita income in poor and rich countries will converge (Shahbazi and Hamidi Zari 2014, p. 177-178).

There are three distinct ways in economic growth literature to examine convergence; beta convergence, sigma convergence and stochastic convergence. Beta 
convergence implies that poor economies have higher rate of growth and in similar economic structures all countries will have convergent on per capita income. Sigma convergence refers to a reduction in the dispersion of levels of income across economies. Stochastic convergence refers to disturbances by external shocks.

Within the last decades, we have witnessed emergence of a variety of theories on and policies towards economic growth and income distribution. In 1950s and 1960s, Hirschman (1958) and many others felt that economic growth could lead to equal distribution of income, and focused on deploying strategies for economic development. However, in late 1960s and early 1970s, Adelman and Morris (1973) proved that economic growth does not necessarily lead to equal distribution of income. Thus, income distribution became an important goal in economic plans and local policy-making. To achieve local justice within social justice, we need to have an equal system of income distribution to care for local needs. Moreover, resources need to be allocated in a way that maximize incremental coefficient between regions; additional resources should be allocated to alleviate social as well as physical problems. On the other hand, economic and institutional mechanisms should improve the quality of life in deprived regions to ensure equal distribution of income (Arsalanbod 2004, p. 143-144).

Evidence shows that many factors contribute to economic inequality. Kaasa (2003) classifies these factors into five groups: demographical, political, historical, cultural and economic. Kuznets (1955) was the first to investigate effects of development on inequality. He noted that, in early stages of economic development, inequality of income distribution increases, then balances and finally decreases (Abu Nouri and Khoshkar 2008, p. 67). Income inequality is measured using dispersion coefficient index, deviation from relative mean, deviation from relative average, variance of the logarithm of income, Gini coefficient, Thiel index and Atkinson index using household costs data. The Gini coefficient as a variable to measure inequality of income distribution is highly important and better than other measures (Abu Nouri and Zoogi 2013, p. 14). This is because economic development and equal distribution of income are a key to improving quality of life and promoting welfare in the society (Vafaei et al. 2017, p. 83).

Kuznets developed the idea of convergence of income distribution in 1995 based on following justifications: (1) developing countries with low initial inequality will experience increased inequality in the long run; (2) developed countries will initially experience inequality, but it will decrease over time; (3) predicted long-term inequality will decrease for all countries. Empirical evidence does not comply with Kuznets' conception.

Huang et al. (2007) reported an inverted relationship between GDP and inequality of income distribution in countries with mild income inequality, but not for ones with too high/low-income inequality. Bhattacharya (2011) found that Gini coefficient may initially increase and later decrease while inequality increases. The Kuznets hypothesis is implicitly in agreement with convergence of income distribution, which can be proved by Convergence of Income Distribution Test. Tselios (2009) argues that capital flow is greater for high-income (lower inequality) than low-income (high-inequality) countries, where spatial diversity decreases and per capita income converges with income distribution. Moreover, people migrate to high-income regions in search of a better job opportunity, and this leads to long-term convergence of income distribution. 
Gallup (2012) has a different line of reasoning. He holds that increased income leads to more democratic participation. Political activists from low-income community tend to change income distribution by changing tax rate, healthcare system, and increasing educational budget. These redistributive policies allow for convergence of income distribution in unequal settings. However, this is rare in the literature. Most of the studies examine convergence in a certain country or across a group of countries and rarely focus on different levels of one country. Convergence of income distribution is an important measure for evaluating policies of developers because divergence in different regions widens the class gap and inequality in society. That is why policy-makers seek to increase convergence of income distribution in different regions, which occurs when growth rate is accelerated and balanced development is facilitated in underdeveloped and poor regions (Vafaei et al. 2017, p. 88).

As far as justice-related issues are concerned in the history of political thought, the most important issue has been to defend unequal relations in society. Inequality in wealth and social power, despite the similarity in the talents of most people, has been the undeniable fact of all societies. Furthermore, there has been no significant relationship between inequality in wealth and power and inequality in natural talents. So, defending these inequalities or negating them is the key to justice. In other words, justice in political philosophy is a matter that has been raised at the level of social institutions. The legal dimension of justice is judged in fair decisions. It is a fair decision that is in accordance with the law. But as a matter of political philosophy, the question of the justness of the law itself is immediately raised. Distributive justice is the duty of the government to the people and determines the distribution of jobs and public property. In fact, the sense of fair justice faced by people is fairly perceived by the consequences. It is considered as a potential factor with important applications in various fields of organization and society. A large amount of research on justice historically focuses on the distribution of payments and work-related rewards derived from equality theory.

When individuals of an organization judge the extent to which the consequences are right and ethical, they judge the extent to which distributive justice is observed in the organization. Lundahl (2016) discusses distributive justice from the point of view of the people who perform the assignment. And in procedural justice, as the process of research in social psychology changes from the emphasis on the results of allocation of rewards (distributive justice) to the emphasis on the mastery of these allocations, similar changes were made in the study of justice. Earlier, the extent to which justice was shared in the distribution of consequences was only a decisive factor in justice. But due to the changes made to perceived justice, the processes assigned to them are also important and in many cases are considered as the most important determinant of the perception of justice. In the following, a brief review of studies on convergence is provided.

Epstein et al. (2007) studied income distribution in 115 countries using beta-type convergence during 1950-1980 and reported positive results.

Albu (2012) examined convergence of Gini coefficient in two groups of EU countries during 2000-2011 and found that one group was convergent while the other was divergent.

Drastichova and Ostrava (2012) studied economic convergence affected by financial crisis of EU countries from 2001 to 2012 using beta and sigma convergence. He 
asserted beta convergence, but noted that sigma convergence was different from standard deviation of GDP.

Chambers and Dhongde (2016) evaluated income distribution in 81 countries using beta-type convergence during 1990-2010 and reported convergence towards the middle.

Kasraei (2007) studied spatial $\beta$ convergence in 38 countries from Organization of Islamic Conference during 1980-2000. Results indicated convergence at rate 0.44.

Abrishami et al. (2008) studied spatial beta and sigma convergence of energy efficiency in Islamic countries during 1998-2003 and reported positive results.

Mojarad et al. (2013) performed an analysis of $\beta$ convergence in agricultural sector of ECO countries during 1996-2011 using systemic generalized method of moment and found beta convergence at the rate of 0.15.

Daei-Karimzadeh and Karimian (2014) studied income convergence as the gap in per capita income of business partners in D8 countries during 1965-2009 using sigma convergence, tile test, and unit-root test, and reported positive convergence between these countries.

Saadati and Mohseni (2014) studied Islamic convergence in Persian Gulf nations during 1998-2008 using generalized least squares and gravity model. They realized that economic cooperation between these countries increases bilateral trades and economic convergence. However, decreasing income gap had no effects on increasing trades.

Shahbazi et al. (2015) examined economic convergence in member states of the Organization for Economic Co-operation during 1990-2010 using beta and sigma convergence and spatial econometrics and found positive spatial overflow and beta convergence, but no sigma convergence.

Masoomzadeh et al. (2017) examined industrial spatial $\beta$ convergence in Iran's provinces from 2007 to 2017 and reported both absolute and conditional convergence.

Masoomzadeh et al. (2018) investigated convergence of income distribution in provinces of Iran during the years 1996-2014 using Nahar and Inder method. The results of their study indicated convergence of income distribution in some provinces and divergence in others.

A close analysis of the literature on income distribution and convergence reveals that a great majority of studies focus on economic growth convergence using beta and sigma convergence, unit-root tests and panel data. Convergence of income distribution as an index of economic justice is rarely studied, and no subtle study has been done by far to analyze convergence of Gini coefficient in Islamic countries. Thus, the present study is the first of its kind to examine convergence of Gini coefficient and income distribution in Islamic countries.

\section{Methodology}

The present study analyzes convergence of income distribution as an index of Islamic justice in selected Islamic countries (Albania, Bangladesh, Azerbaijan, Egypt, Guinea, Iran, Iraq, Jordan, Kazakhstan, Kosovo, Kyrgyzstan, Malaysia, Maldives, Niger, Pakistan, Senegal, Tajikistan, Turkey, Yemen And Tunisia) during 1995-2015 using absolute $\beta$ convergence. Data were obtained from World Data Bank. 


$$
\log \left(\frac{y_{i, t}}{y_{i, t-1}}\right)=a-\beta \log \left(y_{i, t}\right)+u_{i, 1}
$$

where $y_{i, t}$ denotes difference of each country's Gini coefficient from the mean in year $t ; y_{i, t-1}$ denotes $i$ country's Gini coefficient from the mean in year-1. Positive $\beta$ coefficient implies an inverted relationship between initial state and mean growth rate. That is to say, countries with low Gini coefficient move at a higher rate than other countries towards middle point. On the other hand, negative $\beta$ coefficient denotes divergence. $\beta$ convergence coefficient shows rate of convergence.

Conditional beta convergence includes control variables and is determined by:

$$
\log \left(\frac{y_{i, 1}}{y_{i, 0}}\right)=a-\beta \log \left(y_{i, 0}\right)+\sum \gamma x_{i, 1}+u_{i, 1}
$$

where $y_{i, t}$ is the difference in each country's Gini coefficient from total Gini coefficient in year $t . y_{i, t-1}$ is the difference in country $i$ th Gini coefficient from total Gini coefficient of all countries in year $t-1$. Control variables are inflation rate, and GDP per capita. Inflation rate is calculated from consumer price index.

The important thing in estimating panel data is whether specific effects are fixed or random. The principal assumption is that panel data models are random effects independent from explanatory variables. Nevertheless, this assumption is rejected and it is inappropriate to use random effects in estimation. The relationship between specific effects and explanatory variables in fixed effects method is not problematic. But fixed effects method has a dynamic structure and yields inconsistent estimations (Arellano 1993; Arellano and Bond 1991).

Since the explanatory variable is endogenous and the model has a dynamic structure, generalized method of moment is used here because it uses variable lag to remove endogenous bias.

Before performing convergence test, we need to provide income distribution in the countries under study. Table 1 gives descriptive statistics of Gini coefficient (low, mean, high) as an index of income distribution and Islamic justice.

As can be seen, Kyrgyzstan and Maldives score the highest (49) while Azerbaijan scores the lowest (16) Gini coefficient. Moreover, Albania and Kosovo show equal

Table 1 Descriptive statistics of Gini coefficient during 1995-2015. Source: research findings

\begin{tabular}{llllllll}
\hline Country & Max & Min & Mean & Country & Max & Min & Mean \\
\hline Albania & 31.9 & 26.8 & 29.44 & Kyrgyzstan & 26.8 & 49.7 & 33.74 \\
Bangladesh & 31 & 33.4 & 32.58 & Malaysia & 45.8 & 49.2 & 47.39 \\
Azerbaijan & 16 & 36.1 & 28.57 & Maldives & 37.5 & 43 & 40.3 \\
Egypt & 29 & 32.9 & 31.32 & Niger & 31.5 & 44.4 & 39.29 \\
Guinea & 33 & 45.5 & 39.67 & Pakistan & 28.5 & 33.1 & 30.88 \\
Iran & 37.4 & 44.1 & 42.28 & Senegal & 39.2 & 42.9 & 40.70 \\
Iraq & 28.1 & 30 & 29.10 & Tajikistan & 28 & 34 & 30.69 \\
Jordan & 32 & 37 & 34.66 & Turkey & 38.4 & 42.6 & 40.42 \\
Kazakhstan & 26.3 & 35.8 & 31.24 & Yemen & 34.4 & 43.9 & 35.67 \\
Kosovo & $3 / 26$ & $3 / 33$ & $19 / 30$ & Tunisia & $5 / 33$ & $7 / 41$ & 37.86 \\
\hline
\end{tabular}


Table 2 Descriptive statistics of income per capita during 1995-2015. Source: research findings

\begin{tabular}{lrrrlrrr}
\hline Country & Max & Min & Mean & Country & Max & Min & Mean \\
\hline Albania & 4225 & 1676 & 3142 & Kyrgyzstan & 1019 & 535 & 778 \\
Bangladesh & 1002 & 459 & 669 & Malaysia & 10,912 & 6277 & 8194 \\
Azerbaijan & 6072 & 1234 & 3636 & Maldives & 7642 & 4599 & 6388 \\
Egypt & 2703 & 1658 & 2236 & Niger & 386 & 322 & 344 \\
Guinea & 750 & 573 & 653 & Pakistan & 1082 & 806 & 924 \\
Iran & 6698 & 4464 & 5605 & Senegal & 1383 & 1021 & 1199 \\
Iraq & 5508 & 2329 & 4154 & Tajikistan & 935 & 356 & 616 \\
Jordan & 3784 & 2654 & 3213 & Turkey & 13853 & 7315 & 9908 \\
Kazakhstan & 3738 & 10,646 & 7151 & Yemen & 1334 & 908 & 1164 \\
Kosovo & 3802 & 1920 & 3501 & Tunisia & 4308 & 2429 & 3507 \\
\hline
\end{tabular}

Table 3 Instrument validity test. Source: research findings

\begin{tabular}{ll}
\hline$x^{2}$ & 18.5021 \\
prob $>\chi^{2}$ & 1.000 \\
\hline
\end{tabular}

Table 4 Autocorrelation of Arellano and Bond. Source: research findings

\begin{tabular}{lcc}
\hline Lag & $\boldsymbol{Z}$ & $\boldsymbol{p r}>\boldsymbol{z}$ \\
\hline First & -3.84 & 0.000 \\
Second & 0.68 & 0.497 \\
\hline
\end{tabular}

income distribution while in Malaysia the Gini coefficient is 47, implying high inequality of income distribution (Table 2).

Descriptive statistics of income per capita for countries under study are given below (Table 2).

The table shows that Malaysia and Tajikistan, respectively, have maximum and minimum pe capita income.

\section{Results}

The present study analyzes absolute $\beta$-convergence of Gini coefficient as an index of Islamic justice in selected Islamic countries during 1995-2015 using generalized method of moment and Stata 13. Sargan test was applied to validate the used instruments. Results are given in Table 3. Then, the model was estimated in terms of instrumental variables. Finally, autoregressive error terms were tested. Results are given in Table 4.

Table 3 shows results of Sargan test for instrument validity in the model. Thus, $H_{0}$ on instrument validity is not rejected here and the used instruments are valid.

Table 4 shows that $H_{0}$ regarding non-existence of autoregressive error terms is not rejected and the $z$-statistics for autocorrelation lag of first and second order were found to be 0.66 and -1.5 , respectively. Thus, $H_{0}$ on non-existence of second-order autocorrelation at significant level of $1 \%$ is not rejected. 
Table 5 Results of absolute $\beta$ convergence. Source: research findings

\begin{tabular}{lccr}
\hline Variable & Coefficient & z-Statistics & Prob \\
\hline$X$ & 0.3123207 & 553.05 & 0.000 \\
Cons & -0.0017288 & -15.26 & 0.000 \\
\hline
\end{tabular}

Table 6 Instrument validity test. Source: research findings

\begin{tabular}{ll}
\hline$x^{2}$ & 18.17838 \\
prob $>x^{2}$ & 1.000 \\
\hline
\end{tabular}

Table 7 Autocorrelation of Arellano and Bond. Source: research findings

\begin{tabular}{lcc}
\hline Lag & $\boldsymbol{Z}$ & $\boldsymbol{p r}>\boldsymbol{z}$ \\
\hline First & -1.62 & 0.000 \\
Second & 0.98631 & 0.3240 \\
\hline
\end{tabular}

Results of $\beta$ convergence show that $\beta$ coefficient is 0.3123207 and imply convergence of Gini coefficient in Islamic countries. Convergence rate is 0.31 and convergence coefficient is significant at $1 \%$. Moreover, $y$-intercept is significant at significance level of $1 \%$ (Table 5).

Results of estimations by conditional beta convergence are given below.

Before model estimation, Sargan test was applied to validate the used instruments (Table 6). Then, the model was estimated in terms of instrumental variables. Finally, autoregressive error terms were tested. Results are given in Table 6.

Table 6 shows results of Sargan test for instrument validity in the model. Thus, $H_{0}$ on instrument validity is confirmed and the used instruments are valid.

Table 7 shows that $H_{0}$ regarding non-existence of autoregressive error terms is not rejected and the $z$-statistics for autocorrelation lag of first and second order were found to be -1.062 and 0.98631 , respectively. Thus, $H_{0}$ on non-existence of second-order autocorrelation at significant level of $\% 1$ is confirmed.

Results of conditional $\beta$ convergence indicate convergence of Gini coefficient in Islamic countries at convergence rate of 0.33 . Convergence coefficient is significant at $1 \%$. Moreover, $y$-intercept is significant at significance level of $1 \%$. Control variables are also considered. Inflation rate $(0.0000414)$ has positive effects on convergence of Gini coefficient in countries under study. It is statistically significant at confidence level of $1 \%$. GDP is also influential on Gini convergence and 1\% increase in GDP increases convergence by 0.002 . It is statistically significant at confidence level of $1 \%$ (Table 8 ).

\section{Conclusion}

Given the importance of fair distribution as a measure of Islamic economic justice and equal distribution of income in Islamic countries, the present study investigated economic convergence of Islamic justice in selected Islamic countries (Albania, Bangladesh, Azerbaijan, Egypt, Guinea, Iran, Iraq, Jordan, Kazakhstan, Kosovo, Kyrgyzstan, 
Table 8 Results of conditional $\beta$ convergence. Source: research findings

\begin{tabular}{llll}
\hline Variable & Coefficient & z-statistics & Prob \\
\hline$x$ & 0.33 & $241 / 22$ & 0.000 \\
Ir & 0.0000141 & 13.12 & 0.000 \\
Gdp & 0.002 & 1.77 & 0.077 \\
Cons & -0.004 & -14.36 & 0.000 \\
\hline
\end{tabular}

Malaysia, Maldives, Niger, Pakistan, Senegal, Tajikistan, Turkey, Yemen And Tunisia) during 1995-2015 using generalized method of moment and Stata 13 software. Our results indicated that income distribution in 20 countries under study was convergent at the rate of 0.31 and was significant at $1 \%$. Results of conditional beta convergence implied convergence of Gini coefficient in these countries. Inflation rate and per capita GDP had positive effects on Gini coefficient.

\section{Discussion}

The present study investigated economic convergence of Islamic justice in selected Islamic countries during 1995-2015 using generalized method of moment and Stata 13 software. Our results indicated that income was convergent at the rate of 0.31 . Results of the present study were in agreement with findings of similar studies. For example, Albu (2012) studied convergence of Gini coefficient in EU countries during 2000-2011 and reported convergence in control group and divergence in experimental group. Similarly, Chambers and Dhongde (2016) studied convergence of Gini coefficient in some countries and reported that they were convergent. It is suggested that Organization of Islamic Countries develop proportionate plans and policies to optimize efficiency of assets of poorer economies, e.g., through access to complementary assets. Moreover, price adjustment policies can help promote efficiency and improve income distribution in divergent regions. Thereby, prices in divergent regions decline and inequality significantly drops in the long run, leading finally to a more convergent income distribution. Optimal use of capital in income distribution in divergent regions may have positive effects on achieving convergence. Countries which suffer from inequality are suggested to formulate plans for economic, social and local development and allocate financial resources to increase job opportunities. Financial moderators, like increasing retirement pensions and unemployment insurance in times of high inflation, may help curve the gap in distribution. Increasing direct tax from total tax in divergent countries, where the ratio of tax income to GDP is low, is also helpful. This way, the government can optimally use taxes from high-income entities to redistribute income and drive the low Gini coefficient upwards.

Acknowledgements

In the present study, no organization has been used, therefore it is not necessary to thank any organization or individual.

Authors' contributions

This study is the result of the sole author's research mentioned in cartbot. The author read and approved the final manuscript.

Funding

This study lacks financial resources and competitive resources.

Availability of data and materials

The survey data in the research is from WDI. 


\section{Competing interests}

The author declares no competing interests.

Received: 27 April 2019 Revised: 26 December 2019 Accepted: 3 February 2020

Published online: 11 March 2020

\section{References}

Abrishami H, Alam al-Hoda N, Meysam A (2008) The study of the convergence of energy efficiency in Islamic countries during 1980-2003 by spatial econometric method. J Energy Econ 4(15):7-34

Abu Nouri I, Khoshkar A (2008) Effect of macroeconomic indicators on income distribution in Iran: inter-provincial study. Econ Res Mag 77:67-95

Abu Nouri l, Zoogi E (2013) Estimating and comparing income distribution inequality by parametric and nonparametric methods. Macroecon Res 8(16):13-30

Adelman I, Morris CT (1973) Economic growth and social equity in developing countries. Stanford University Press, Stanford

Albu LL (2012) The convergence in the EU estimated by Gini coefficient. Romanian J Econ Forecast 4:5-16

Arellano M (1993) On testing of correlation effects with panel data. J Econ 59:87-97

Arellano M, Bond S (1991) Some tests of specifications for panel data: Monte Carlo evidence and an application to employment equations. Rev Econ Stud 58:277-297

Arsalanbod MR (2004) Changes in income distribution in rural and urban areas of Iran. Agric Econ Dev 12(45):141-147

Bhattacharya P (2011) Informal sector, income inequality and economic development. Econ Model 28:820-830

Chambers D, Dhongde SH (2016) Convergence in income distributions: evidence from a panel of countries. Econ Model 59:262-270

Daei-Karimzadeh S, Karimian Q (2014) Financial policy and convergence of working force efficiency. Q J Econ Dev 3(9):57-72

Drastichova M, Ostrava VT (2012) The relations of real and nominal convergence in the EU with impacts on the Euro area participation. Central Eur Rev Econ Issues 15(1):107-122

Epstein PH, Howlett P, Schulze MS (2007) Trade, convergence, and globalization: the dynamics of the international income distribution, 1950-1998. Explor Econ Hist 44:100-113

Eivazlou H (2010) A review of social and economic justice criteria in adaptation to the Islamic law. Islamic Econ Stud 2(2):5-26

Hirschman AO (1958) The strategy of economic development. Yale University Press, New Haven

Huang H, Lin S, Suen Y, Yeh C (2007) A quintile inference of the Kuznets hypothesis. Econ Model 24:559-570

Kaasa A (2003) Factors influencing income inequality in transition Economics. University of Tartu Faculty of Economics and Business Administration, www.tyk.ut.ee, Order No. 207

Kasraei I (2007) Convergence theory, spatial dependence and regional growth (evidence from the organization of the Islamic conference for the use. Q J Econ Res 12(77):27-64

Kuznets S (1955) Economic growth and income inequality. Am Econ Rev 45:1-28

Lundahl L (2016) Equality, inclusion and marketization of Nordic education: introductory notes. Res Comp Int Educ 11(1):3-12

Masoomzadeh S, Shirafkan M, Sayareh M (2017) The study of industrial convergence in Iran's provinces: spatial econometric approach (SDM). J Econ Model 11(2):177

Masoomzadeh S, Shirafkan M, Mohammadnejhadi M (2018) Study of convergence of income distribution in Iran provinces. J Econ Model 12(41):146-162

Mojarad E, Homayoun Far M, Salarpour M (2013) The role of agriculture in the regional convergence of eco countries. J Econ Res 2007(4):189

Ramsey FP (1928) A mathematical theory of saving. Econ J 28(152):543-549

Saadati R, Mohseni N (2014) Economic convergence of Iran and Caspian Sea nations using gravity model. Q J Trades 20(73):29-53

Sajjadi SJ (1983) Islamic culture, vol 3. Translators \& Translators Co, Tehran

Shahbazi K, Hamidi Zari D (2014) Energy intensity convergence between OPEC member countries (a bilateral approach). Q J Econ Res Policy 22(71):173-198

Shahbazi K, Rezaei E, Hamidi Zari D (2015) Economic convergence of ECO countries: spatial econometrics. Q J Econ Res Policy 22(71):155-196

Solow RM (1956) A contribution to the theory of economic growth. Q J Econ 70(1):65-94

Swan T (1956) Economic growth and capital accumulation. Econ Rec 32(2):334-361

The Committee of Annuity Insurers (2013) Survey of owners of individual annuity contracts (The Gallup Organization and Matthew Greenwald \& Associates). http://www.annuity-insurers.org/wp-content/uploads/2013/10/2013-Gallu p-Survey.pdf. Accessed 12 June 2014

Tselios V (2009) Growth and convergence in income per capita and income inequality in the regions of the EU. Spat Econ Anal 4:343-370

Vafaei E, Mohammadzadeh P, Fallahi F, Asgharpour H (2017) Surveying convergence of social welfare in Iran provinces using non-linear technique of space star. Q J Appl Econ Theory 4(2):79-102

\section{Publisher's Note}

Springer Nature remains neutral with regard to jurisdictional claims in published maps and institutional affiliations. 